Supporting Information:

\title{
Realizing high thermoelectric performance in GeTe through optimizing Ge vacancies and manipulating Ge precipitates
}

Yang Jin, ${ }^{1}$ Yu Xiao, ${ }^{1}$ Dongyang Wang, ${ }^{1}$ Zhiwei Huang, ${ }^{1}$ Yuting Qiu, $2,{ }^{2,}$ Li-Dong Zhao ${ }^{1, *}$

${ }^{1}$ School of Materials Science and Engineering, Beihang University, Beijing 100191,

China

${ }^{2}$ Beihang School, Beihang University, Beijing 100191, China

Corresponding authors: qyt2014@buaa.edu.cn; zhaolidong@buaa.edu.cn 


\section{Experimental details}

Synthesis: High purity raw elements $\mathrm{Ge}, \mathrm{Bi}, \mathrm{Te}$ were weighted in stochiometric proportions and sealed in quartz tubes under vacuum $\left(<\sim 10^{-}\right.$ ${ }^{4}$ Torr). The tubes were slowly heated up to $1373 \mathrm{~K}$ and held at $1373 \mathrm{~K}$ for $6 \mathrm{~h}$, then subjected to furnace cooling or cold-water quenching to room temperature. The ingots after cold water quenching were annealed at 873 $\mathrm{K}$ for $3 \mathrm{~d}$. The ingots were ground into powders and then densified by sparks plasma sintering system (SPS-211Lx) at $773 \mathrm{~K}$ under a pressure of $50 \mathrm{MPa}$ for $5 \mathrm{~min}$. High densities (>95\% of the theoretical density) were obtained for all samples. The densified cylinder-shaped samples with dimension $\Phi 12.7 \mathrm{~mm} \times 10 \mathrm{~mm}$ was obtained, which is assured enough thickness for preparing test samples along the direction that is perpendicular to the spark plasma sintering pressure direction.

Phase structure and microstructure characterization: The phase purity and crystal structure were analyzed by the powder X-ray diffraction (XRD) with $\mathrm{Cu} \mathrm{K \alpha}(\lambda=1.5418 \AA)$ radiation. Phase composition analysis was carried out by scanning electron microscope (ZEISS Supra 55), which was equipped with an energy dispersive X-ray spectrometer (EDS).

Thermoelectric transport properties: Both Seebeck coefficient and electrical conductivity were measured using Cryoall CTA instrument under a low-pressure helium atmosphere from room temperature to $773 \mathrm{~K}$. The thermal conductivity was calculated through $\kappa=D^{\cdot} C_{P} \cdot \rho$, where $D, C_{P}, \rho$ 
are thermal diffusivity, heat capacity and sample density, respectively. The $D$ is measured by laser flash diffusivity method using an instrument LFA 457 (NETZSCH, Germany) as shown in Figure S2a. The $C_{P}$ was estimated with the Dulong-Petit law. The sample density was determined using the dimensions and mass, as shown in Table S1. Hall coefficients $\left(R_{\mathrm{H}}\right)$ were measured with the Van der Pauw method in Lake Shore 8400. Carrier concentration $\left(n_{\mathrm{H}}\right)$ and carrier mobility $\left(\mu_{\mathrm{H}}\right)$ were estimated by $n_{\mathrm{H}}=1 /\left(e R_{\mathrm{H}}\right)$ and $\mu_{\mathrm{H}}=\sigma \cdot R_{\mathrm{H}}$, respectively.

Lorenz number calculations: a single parabolic band (SPB) model with acoustic phonon scattering was used to estimate Lorenz number $(L)$. It is well known that the $L$ value can estimate the lattice thermal conductivity, which will not change the total thermal conductivity and final ZT values. The Lorenz number is given by the formula ${ }^{1}$ :

$$
L=\left(\frac{k_{B}}{e}\right)^{2}\left(\frac{(r+7 / 2) F_{r+5 / 2}(\eta)}{(r+3 / 2) F_{r+1 / 2}(\eta)}-\left[\frac{(r+5 / 2) F_{r+3 / 2}(\eta)}{(r+3 / 2) F_{r+1 / 2}(\eta)}\right]^{2}\right)
$$

where $\mathrm{k}_{\mathrm{B}}$ is the Boltzmann constant and $\eta$ represents the reduced Fermi energy, which can be derived from the measured Seebeck coefficients via the following equations:

$$
S= \pm \frac{k_{B}}{e}\left(\frac{(r+5 / 2) F_{r+3 / 2}(\eta)}{(r+3 / 2) F_{r+1 / 2}(\eta)}\right)
$$

where $F_{n}(\eta)$ is the nth order Fermi integral: 


$$
\begin{gathered}
F_{n}(\eta)=\int_{0}^{\infty} \frac{\chi^{n}}{1+e^{\chi-\eta}} d \chi \\
\eta=\frac{E_{f}}{k_{B} T}
\end{gathered}
$$

Acoustic phonon scattering is the main carrier scattering mechanism, resulting in $r$ value of $-1 / 2$. 
Table S1: Sample densities $\left(\mathrm{g} / \mathrm{cm}^{3}\right)$ for $\mathrm{Ge}_{1-x} \mathrm{Bi}_{x} \mathrm{Te}$ before and after heat treatment.

\begin{tabular}{ccc}
\hline $\mathrm{Ge}_{1-x} \mathrm{Bi}_{x} \mathrm{Te}$ & $\begin{array}{c}\text { Before heat } \\
\text { treatment }\end{array}$ & $\begin{array}{c}\text { After heat } \\
\text { Treatment }\end{array}$ \\
\hline$x=0$ & 6.04 & - \\
$x=0.02$ & 6.07 & 5.90 \\
$x=0.06$ & 6.17 & 6.11 \\
$x=0.10$ & 6.23 & 6.27 \\
\hline
\end{tabular}


(a)

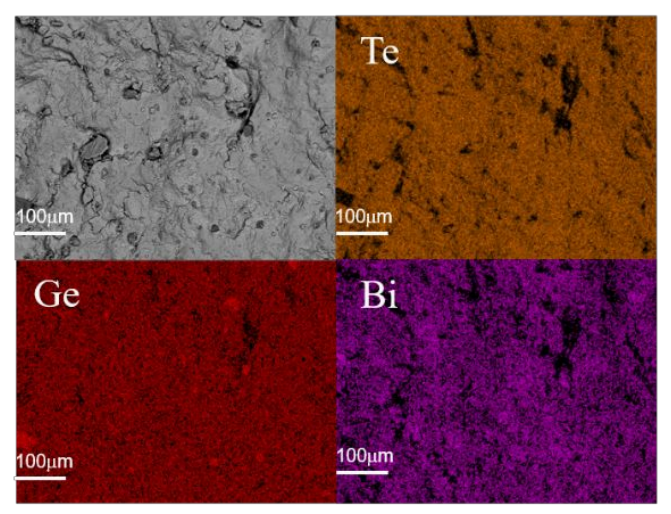

(b)

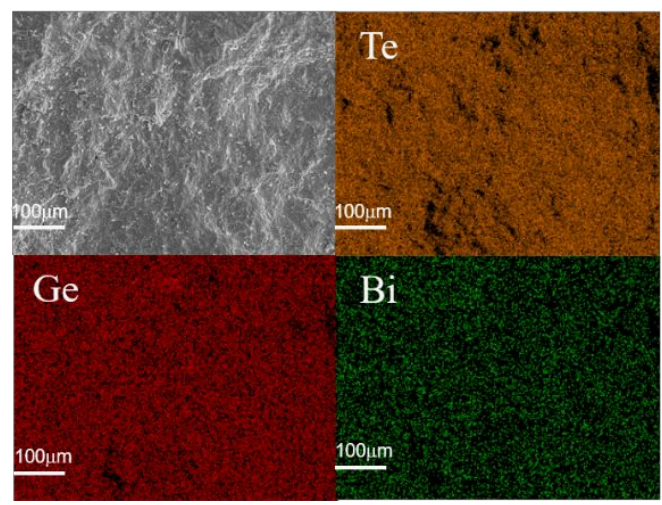

Figure S1: Secondary electron images and secondary X-ray maps for (a) furnacecooled and (b) heat-treated $\mathrm{Ge}_{0.94} \mathrm{Bi}_{0.06} \mathrm{Te}$. 
(a)

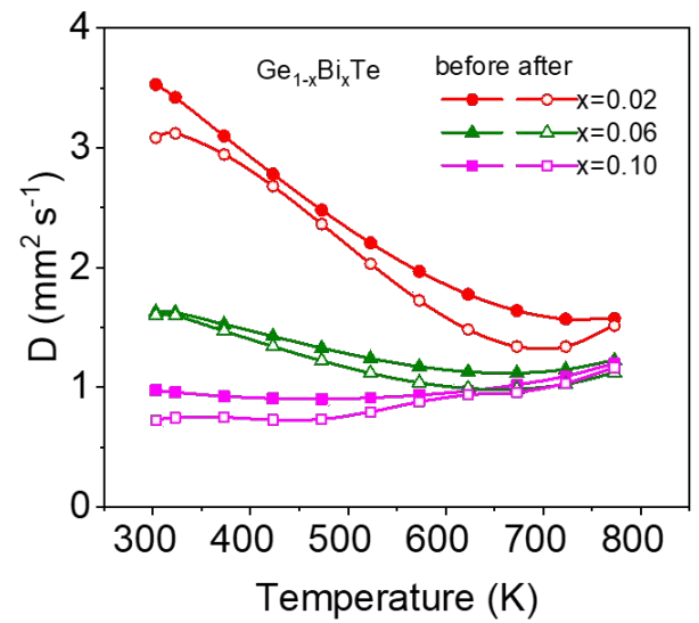

(b)

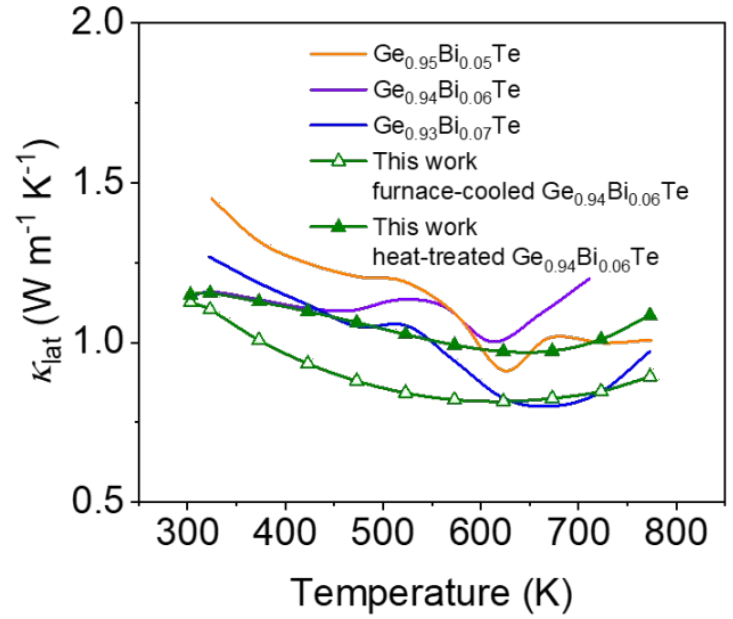

Figure S2: (a) Thermal diffusivity of $\mathrm{Ge}_{1-x} \mathrm{Bi}_{x} \mathrm{Te}(x=0.02,0.06$ and 0.10$)$ before and after heat treatment. (b) Comparisons of lattice thermal conductivity in this work and the reported furnace-cooled $\mathrm{Ge}_{1-x} \mathrm{Bi}_{x} \mathrm{Te}(x=0.05,0.06,0.07)^{2-3}$. 


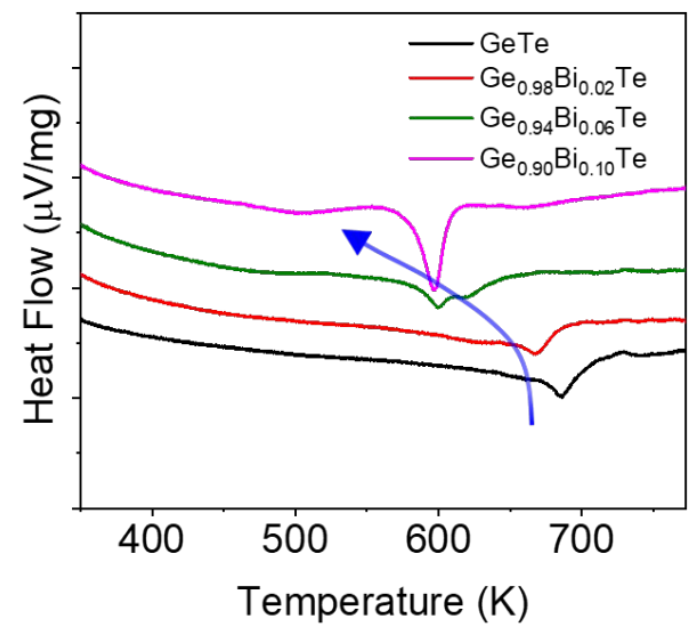

Figure S3: The differential scanning calorimetry (DSC) analysis of heat-treated $\mathrm{Ge}_{1-}$ ${ }_{x} \mathrm{Bi}_{x} \mathrm{Te}(x=0.02,0.06$ and 0.10$)$, the phase transition temperature was shifted to lower temperature with increasing Bi fractions.

\section{Reference}

(1) Chang, C.; Wang, D.; He, D.; He, W.; Zhu, F.; Wang, G.; He, J.; Zhao, L.-D. Realizing High-Ranged Out-of-Plane ZTs in N-Type SnSe Crystals through Promoting Continuous Phase Transition. Advanced Energy Materials 2019, 9 (28), 1901334.

(2) Perumal, S.; Roychowdhury, S.; Biswas, K. Reduction of thermal conductivity through nanostructuring enhances the thermoelectric figure of merit in $\mathrm{Ge}_{1-\mathrm{x}} \mathrm{Bi}_{\mathrm{x}} \mathrm{Te}$. Inorganic Chemistry Frontiers 2016, 3 (1), 125-132.

(3) Wu, D.; Feng, D.; Xu, X.; He, M.; Xu, J.; He, J. Realizing high figure of merit plateau in $\mathrm{Ge}_{1-\mathrm{x}} \mathrm{Bi}_{\mathrm{x}} \mathrm{Te}$ via enhanced $\mathrm{Bi}$ solution and Ge precipitation. Journal of Alloys and Compounds 2019, 805, 831-839. 